\title{
O ataque organizado à ciência como forma de manipulação: do
} aquecimento global ao coronavírus

\author{
Gabriela Fasolo Pivaro ${ }^{1}$ \\ Doutoranda no Programa de Pós-Graduação Multiunidades em \\ Ensino de Ciências e Matemática \\ Gildo Girotto Júnior ${ }^{1}$ \\ Universidade Estadual de Campinas \\ Campinas - SP
}

\section{Resumo}

A época da pós-verdade descreve tempos de uma subjetificação da realidade, em que fatos são manipulados e escolhidos de acordo com crenças pessoais previamente estabelecidas. Considerando as interferências no campo político e que culminam no acesso de personalidades extremistas ao comando de governos, para melhor compreender a pós-verdade é necessário olharmos como, antes dela, o negacionismo científico foi usado como estratégia política de manipulação da verdade. Neste artigo, fazemos uma sumarização histórica das origens do negacionismo até os tempos atuais, relacionando semelhanças entre diferentes governos, e discutimos como o desgaste da verdade foi influenciado pelas redes sociais. Apresentamos exemplos do negacionismo bolsonarista referente ao novo coronavirus para dialogar com nossos referenciais e por fim, expomos algumas reflexões sobre como a divulgação científica pode alcançar o outro lado da denominada bolha ideológica.

Palavras-chave: Negacionismo Científico; Pós-Verdade; Coronavírus.

\footnotetext{
${ }^{+}$The organized attack on science as a form of manipulation: from global warming to the coronavirus

* Recebido: junho de 2020. Aceito: setembro de 2020.

${ }^{1}$ E-mails: gfpivaro@gmail.com; ggirotto@unicamp.br
} 


\begin{abstract}
The post-truth era describes times of a subjectification of reality, in which facts are manipulated and chosen according to the personal beliefs previously established. Considering the interferences in the political field and that culminate in the access of extremist personalities to the command of governments, to better understand the post-truth it is necessary to look at how, before it, scientific negationism was used as a political weapon of manipulation of the truth. In this article, we make a historical summary of the origins of negationism to the present day, relating similarities between different governments, and discuss how the erosion of the truth was influenced by social networks. We present examples of bolsonarist denialism regarding the new coronavirus to dialogue with our references and, finally, we present some reflections on how scientific dissemination can reach the other side of the so-called ideological bubble.
\end{abstract}

Keywords: Science Denial; Post-Truth; Coronavirus.

\title{
I. Introdução
}

Em 2017, o livro 1984 de George Orwell, publicado pela primeira vez em 1949, voltou às listas de mais vendidos após a eleição presidencial norte-americana e a vitória de Donald Trump (ALTARES, 2017). Nesta obra distópica, os habitantes de um mundo em guerra perpétua são vigiados de maneira onisciente por um governo autoritário, que controla e reescreve - as narrativas da história perseguindo liberdades de expressão que não correspondem àquilo que o "Partido" permite. Para controlar as narrativas da história, no romance há o que chamam de "fatos alternativos", como se os acontecimentos pudessem ser subordinados a uma questão de opinião daqueles que detém o poder (no caso, o "Partido"). Para pesquisadores e jornalistas, a campanha e vitória de Trump é um marco da ascensão da pós-verdade, se assemelhando aos "fatos alternativos", na política (ALTARES, 2017; D’ANCONA, 2018; KAKUTANI, 2018; MCINTYRE, 2018).

A pós-verdade possui como uma de suas origens e sustentações o ataque à ciência. Exemplo disto é, também em 2017, o fato da administração Trump proibir que as palavras evidence-based (baseado em evidência) e science-based (baseado na ciência) fossem usadas por oficiais da maior agência de saúde pública dos Estados Unidos, o Centro de Controle e Prevenção de Doenças (CDC) (SUN; EILPERIN, 2017). Na obra orwelliana, o "Partido" recorrentemente ataca a ciência, chegando a excluir a palavra da "Novafala", o idioma fictício criado pelo "Partido". 
A Novafala é descrita no livro como a única língua do mundo cujo vocabulário encolhe a cada ano, feita, dessa maneira, para não permitir que certos pensamentos que necessitam de palavras sejam formulados. Em contraponto à situação descrita no romance, destacamos o papel da educação defendida por Camillo e Mattos (2014, p. 225), de “(...) proporcionar ao educando o enriquecimento e a complexificação das relações que estabelece com o mundo, fazendo com que se aproprie do já estabelecido e, dialeticamente, proporcionando caminhos para a criação do novo a partir do já dado". Ou seja, ao considerarmos que o papel da educação é de proporcionar ao indivíduo a capacidade de enriquecer e complexificar as relações que estabelece com o mundo, e que é através do discurso entre locutores que o sentido se faz e que se apreende a relação entre linguagem e ideologia (ORLANDI, 1994), mostra-se inevitável confrontar o simbolismo de um governo frequentemente associado à pós-verdade com o ato de proibir expressões relacionadas ao pensamento científico. A compreensão da ciência (e educação) e do pensamento científico é, nestes termos, inimiga da pós-verdade.

Seria um erro, e uma ingenuidade, pensar que tal acontecimento em outro país não interfere em nossas vivências brasileiras. Como comenta Kakutani (2018, p. 43), “decisões tomadas pelo governo norte-americano (...) acabam tendo um efeito dominó pelo mundo inteiro". Somando-se a isso, não se pode ignorar que o Brasil possui seu próprio "Trump tropical", expressão utilizada por parte da mídia internacional, e então replicada em alguns portais nacionais, para descrever o presidente Bolsonaro dadas suas tomadas de decisões e seus alinhamentos ideológicos com o presidente norte-americano (BULLA; CHADE, 2018; PHILLIPS, 2018; ASSOCIATED PRESS, 2019; BINDING, 2019; SANT'ANNA, 2020). Neste âmbito, para entender o fenômeno da pós-verdade, é substancial que se entenda o fenômeno da negação da ciência e como esse negacionismo foi usado como uma estratégia de manutenção do sistema neoliberal, apoderado pelo discurso político partidário e fortalecido pelos meios midiáticos.

Deste modo, iniciamos nossas discussões através de uma abordagem histórica de como o negacionismo científico começou a ser utilizado como forma de manipulação da opinião pública pela indústria por motivos econômicos e, obtendo sucesso, suas táticas foram reproduzidas quando necessárias por outras corporações. Utilizando os meios midiáticos para a implementação da dúvida de uma ausência de consensos científicos no imaginário coletivo, os debates acerca dos resultados científicos tornaram-se uma questão de opinião guiada por uma polarização política. Tendo o negacionismo científico fortes raízes e ramos norteamericanos, abordamos semelhanças entre os governos Trump e Bolsonaro para, deles, traçarmos paralelos que nos permitem uma melhor compreensão de como esse fenômeno se manifesta no Brasil. Destacamos que, ao longo deste texto, entendemos a verdade como “(...) a verdade dos fatos, ou seja, aquela que poderia ser objetivamente descrita conforme se apresente no plano material daquilo a que chamamos de fatos" (BUCCI, 2019, p. 15). Permeando esta definição trazemos elementos que permitem, em seguida, abordar as 
características da pós-verdade e sua relação - e extrapolação - com os casos de negacionismo científico e buscamos correlacionar nossa discussão no papel das redes sociais na propagação destes discursos de subjetificação da verdade.

Partindo da consideração que a pós-verdade é um fenômeno multifacetado e complexo, cujos arranjos são frutos de diversas interconexões, não pretendemos, ao longo do texto, discutir todos os aspectos que tornaram, hoje, a sociedade em um mundo de verdades fragmentadas, onde pessoas buscam explicações cada vez mais simplistas e maniqueístas para fenômenos cada vez mais complexos. Esperamos com nosso recorte, contudo, contribuir para o debate sobre a pós-verdade no âmbito nacional e, após uma revisão e discussão com a literatura que versa sobre as origens do negacionismo científico e do desgaste da verdade, apresentar como alguns desses movimentos se exemplificam no Brasil durante a pandemia do novo coronavírus e discutir possíveis caminhos de enfrentamento contra esse novo obscurantismo.

\section{O negacionismo científico como estratégia política}

Como expõe McIntyre (2018, p. 17, tradução nossa), "a pós-verdade foi prenunciada pelo que vem acontecendo com a ciência nas últimas décadas". Antes de nos confrontarmos com os "debates" sobre o formato da Terra, sobre a eficácia ou não das vacinas, sobre as mudanças climáticas e o buraco na camada de ozônio, o discurso negacionista científico teve como alvo a relação entre o consumo de cigarros, câncer e doenças respiratórias. Pode-se dizer que o roteiro sobre como deslegitimar as pesquisas científicas e introduzir no imaginário coletivo dúvidas acerca de consensos científicos foi elaborado pela indústria de tabaco norteamericana e replicado com sucesso desde então.

No início da década de 1950, surgiram pesquisas que reforçaram o elo entre o uso de cigarros e o desenvolvimento de câncer de pulmão e outras doenças respiratórias. Como uma reação a esses resultados, as diferentes companhias de tabaco se uniram para defender a indústria como um todo. Rabin-Havt (2016) descreve a criação da Tobacco Industry Research Committee (Comissão de Investigação da Indústria do Tabaco) como um organismo financiado pela própria indústria do tabaco que portava como missão convencer o público de que não havia provas que relacionavam o uso de cigarros e câncer.

Com a ideia principal de criar uma falsa narrativa de que havia um debate acerca das evidências e de que não havia um consenso científico associando o uso de cigarros às doenças respiratórias, a comissão divulgou, por meio de propagandas pagas em mais de quatrocentos jornais impressos e atingindo mais de 43 milhões de norte-americanos, um panfleto contendo declarações que ofuscaram as pesquisas que informavam o público sobre os perigos do tabaco (RABIN-HAVT, 2016). Dentre essas declarações, destacamos as reivindicações de que: "as pesquisas médicas indicam diversos motivos para a causalidade de câncer de pulmão"; "não há nenhuma prova de que fumar cigarros seja uma dessas causas”; “(...) diversos cientistas 
contestam a validade dos dados estatísticos que relacionam cigarros e doenças” (Idem, p. 34, tradução nossa).

Somou-se a esta estratégia angariar um grupo específico de supostos especialistas que contradiziam o conhecimento científico e alegavam que mais pesquisas deveriam ser realizadas, atacando a credibilidade dos cientistas "do outro lado". Tais argumentos foram repetidos exaustivamente. Deste modo, foi criada a dúvida acerca de um consenso científico e a mídia comercializou a ideia de que havia dois lados de uma mesma história e que ambos possuíam a mesma importância na discussão. Como bem sintetiza D’Ancona (2018, p. 46) “o objetivo não era a vitória acadêmica, mas a confusão popular”. Enquanto houvesse dúvida, a indústria tabagista continuaria vendendo seu produto.

Eventualmente, as evidências associando o uso de cigarros às doenças se tornaram massivas e a Comissão foi desmanchada no final da década de 1990, mas o modelo de como moldar a opinião pública através da dúvida do consenso científico serviu de exemplo para outros casos de negacionismo. Rabin-Havt (2016) cita como essa estratégia foi usada para manipular a opinião pública em discussões sobre mudanças climáticas e controle de armas; Oreskes e Conway (2010) ressaltam, além das mudanças climáticas, como foram moldadas discussões acerca da chuva ácida e do "buraco" na camada de ozônio; e McIntyre (2019) também destaca como esse modelo guiou as discussões sobre aquecimento global e mudanças climáticas associadas. É seguro afirmar que o negacionismo climático é um dos maiores casos de negacionismo científico atual e que a estratégia utilizada é exatamente a mesma, a de criar a "confusão popular".

Cohen (2013) classifica como três os grupos de negacionistas: o literal; o interpretativo; e o implicatório. O primeiro, tal como classificaria um dicionário, literalmente nega que algo está acontecendo ou aconteceu. $\mathrm{O}$ segundo não nega o fato por si só, mas concede uma outra interpretação aos fatos/dados como, por exemplo, uma defesa de que o clima está mudando, mas sem culpa ou participação humana. O terceiro não nega que algo está acontecendo, apenas minimiza suas consequências. Quando nos referimos ao negacionismo, não estamos distinguindo entre as categorias.

Existem semelhanças entre as duas campanhas negacionistas destacadas (campanha pró-tabaco e campanha de negação das mudanças climáticas) das quais são possíveis delinear paralelos. Tanto o lobby do tabaco quanto o do petróleo enfrentavam potenciais prejuízos econômicos devido aos resultados das pesquisas científicas e ambos financiaram pesquisas particulares para confrontar os cientistas de suas épocas. Como ironicamente questiona RabinHavt (2016), se a ciência não é a dona da verdade, por que deveríamos tomar atitudes que prejudicam o bem-estar econômico de fazendeiros e de milhares de trabalhadores da indústria tabagista, bem como dizer às pessoas que elas não deveriam usufruir de um hábito prazeroso? Do mesmo modo, podemos questionar que se não há um consenso científico sobre quais as causas das mudanças climáticas, por que prejudicaríamos as indústrias petrolíferas que tanto fortalecem a economia e fornecem empregos para a população em tempos de crises? 
A indústria do tabaco fez o marketing necessário para evitar prejuízos, mesmo com os responsáveis por essa campanha de difusão de dúvidas sabendo que o que estavam divulgando consistiam em informações falsas (RABIN-HAVT, 2016). Da mesma maneira, a indústria do petróleo também financiou suas próprias pesquisas para desassociar a relação entre o uso do dióxido de carbono como o principal responsável pelo aquecimento global antropogênico, mesmo tendo conhecimento das pesquisas científicas que alertavam sobre as consequências dos combustíveis fósseis desde a década de 1970 (ORESKES; CONWAY, 2010). Mas, como bem atestam Oreskes e Conway (2010, p. 172, tradução nossa), "o que importa na ciência não é o mesmo que importa na política".

Em 1998, quando os representantes das maiores companhias de petróleo dos Estados Unidos se reuniram para discutir as consequência do Tratado de Kyoto, os tópicos discutidos nessa reunião vazaram de maneira quase imediata, dos quais aqui destacamos que, para eles, a "vitória" seria alcançada no momento em que: "a mídia reconhecer que há incertezas nas ciências climáticas”; “(...) o reconhecimento de que há incertezas nas ciências climáticas for considerado "senso comum",; "a mídia cobrir os dois lados da controvérsia sobre as ciências climáticas" (MCINTYRE, 2018, p. 31, tradução nossa). As semelhanças com as táticas usadas pela indústria do tabaco não foram meras coincidências, elas foram copiadas justamente porque funcionaram.

No entanto, há de se ressaltar uma diferença entre essas duas campanhas negacionistas. Ao longo dos anos, na diferença entre elas, houve uma ascensão de programas televisivos claramente partidários nos Estados Unidos, de forma que as mídias televisivas e impressas, pretendendo-se desvincular de uma imagem de parcialidade e evitar a comparação com a mídia claramente partidária, buscaram criar uma imagem de objetividade na tentativa de alcançar uma maior quantidade de espectadores (MCINTYRE, 2018). Para isso, começaram a reportar os "dois lados" de diversos assuntos ditos controversos. Contudo, a intenção de mostrar os dois lados da história caracterizou-se desastrosa para a divulgação científica, criando-se uma falsa equivalência entre discursos, como se ambos os lados tivessem a mesma credibilidade.

As máquinas de desinformação, por outro lado, viram nessas tentativas uma oportunidade de usar os meios midiáticos como forma de propagação de seus discursos. Diferentemente da indústria do tabaco, não era mais necessário gastar-se milhões em propagandas para difundir declarações negacionistas uma vez que, soltando-se a isca da controvérsia, a própria mídia se encarrega de cobrir o assunto.

$\mathrm{O}$ interesse econômico em negar as mudanças climáticas se relaciona com a manutenção do sistema capitalista, uma vez que a preservação ambiental vai contra os princípios de produção e consumo de recursos desenfreados que objetivam o lucro acima de tudo. Assim,

Reconhecer e atribuir relevância à mudança climática implica apoiar medidas como a regulamentação governamental, o aumento de taxas, a interferência do 
Estado nos mercados e alterações no processo produtivo. Tais medidas constituem agenda oposta aos ideais neoliberais defendidos pelas classes hegemônicas conservadoras. Por essa razão, a mudança climática é frequentemente examinada sob a ótica política, em detrimento da científica. Trata-se de interesses relacionados ao modo de produção e à dinâmica do livre mercado (GASTALDI, 2018, p. 10).

Para proteger e evitar uma crise na agenda neoliberal, o discurso negacionista é elaborado e propagado por agentes que servem ao sistema hegemônico, como as corporações privadas, os impérios midiáticos, os lobbies e os partidos políticos. Como menciona Painter (2011), o "ceticismo" é mais entrelaçado na fábrica do tecido político e ideológico nos Estados Unidos do que no resto do mundo. Com doações multimilionárias feitas por companhias de petróleo, gás natural e mineração para membros individuais do Congresso norte-americano, não por acaso há um maior histórico de cobertura pela grande mídia de indivíduos e grupos com discursos negacionistas. Por esses motivos destacados, o país se torna um ponto central para a disseminação e popularização do negacionismo com seus vieses políticos, econômicos e ideológicos e sendo os Estados Unidos uma potência mundial, eles possuem a capacidade de estabelecer os rumos das narrativas internacionais.

Nesse contexto, o jornalismo opinativo norte-americano, muitas vezes mascarado de reportagem imparcial (MCINTYRE, 2018; PAINTER, 2011), na medida em que uma imparcialidade é possível, contribui para a formação de uma polarização ideológica, subvertendo fatos e consensos científicos à uma questão de opinião. Em 2013, um estudo realizado mostrou que $69 \%$ dos entrevistados pelo canal Fox News eram negacionistas das mudanças climáticas e $75 \%$ das menções a respeito das ciências climáticas foram feitas de modo a questioná-las (THEEL; GREENBERG; ROBBINS, 2013). Não por coincidência, em 2014 o canal Fox News foi considerado a fonte de notícias mais confiável entre os conservadores norte-americanos (MCINTYRE, 2018). Tais porcentagens exemplificam como, a partir de um discurso parcial, a mídia é capaz de nutrir uma relação entre estar em um lado do espectro político com acreditar ou não nas evidências científicas. O canal Fox News, afinal, é conhecido por não esconder seu viés ideológico.

Apesar de ser um consenso na comunidade científica a realidade das mudanças climáticas (ORESKES, 2003) e 97\% das publicações a respeito concluírem que o aquecimento global tem raízes antropogênicas (COOK et al., 2103), membros da ala radical do Partido Republicano associam as ciências climáticas a uma conspiração socialista (PAINTER, 2011), desacreditando as pesquisas científicas e colocando um juízo de valor partidário nos seus resultados. Em 2020, uma pesquisa de opinião perguntou aos seus entrevistados se as políticas que visam uma redução dos efeitos das mudanças climáticas fazem mais bem do que mal para: 1. o meio ambiente; e 2. a economia dos Estados Unidos. Entre os democratas, aqueles que concordaram com essas afirmações foram $71 \%$ e $47 \%$, respectivamente, contra 34\% e 15\% dos republicanos (FUNK; KENNEDY, 2020). 
Em outra questão, comparando a porcentagem dos que dizem que a ação humana contribui muito para as mudanças climáticas, classificando por identificação partidária e nível de conhecimento científico, apenas nos democratas houve uma grande variação de respostas. $89 \%$ dos democratas com um alto nível de conhecimento científico disseram que as atividades humanas contribuem muito para uma mudança climática, comparado com $41 \%$ dos democratas com baixo conhecimento científico. Em contraste, 17\% dos republicanos com um alto nível de conhecimento científico concordam com a afirmação, enquanto $25 \%$ dos republicanos com baixo conhecimento científico concordam com a afirmação (Ibidem).

Essa diferença percentual encontrada entre republicanos e democratas e seus níveis de conhecimento científico nos mostra como o negacionismo não é linearmente correlacionado com uma falta de conhecimento sobre o assunto, como inicialmente pode-se querer supor. Como indicam as pesquisas de Kahan (2013) e Kahan, Jenkins-Smith e Braman (2011), as crenças individuais sobre a existência de consensos científicos e a polarização ideológica sobre evidências factuais podem estar relacionadas com os sujeitos manterem suas crenças de acordo com a afinidade e lealdade que possuem com o grupo com o qual se identificam. Assim, em um cenário de polarização política, quanto mais se reforça que um determinado grupo possui certa postura em relação a algo (vemos esse reforço através da mídia), mais intensa essa polarização se torna, sendo indiferente o que diz o consenso científico.

Nos Estados Unidos, uma comparação entre os anos de 2007 e 2010 mostrou que o número de artigos publicados na mídia impressa contendo vozes de negacionismo ${ }^{2}$ ao tratar dos assuntos "mudança climática" ou "aquecimento global" foi de 13\% a 40\% enquanto, no Brasil, o aumento no mesmo período foi de 1\% a 3\% (PAINTER, 2011). Na tentativa de compreensão desta diferença, o autor considera que, durante esses períodos o negacionismo climático era quase inexistente no Brasil, parte devido à ausência de um lobby organizado de indústrias de extração de petróleo (como há nos Estados Unidos) e parte devido à forte cultura de jornalismo científico da época. Citando Claudio Ângelo, ex-editor científico da Folha de S. Paulo, “(...) a imprensa americana cometeu um erro 10 anos atrás ao tratar o ceticismo como um "outro lado"” e "(...) a Folha não precisava fazer o mesmo" (Idem, p. 66, tradução nossa).

É possível que esta imparcialidade supracitada nos meios de divulgação impressos, no Brasil, no fim da década de 2000 tenha se refletido em uma pesquisa de opinião de 2010 que relatou que, para $92 \%$ dos brasileiros a Terra estava ficando mais quente (DATAFOLHA, 2010). A pesquisa foi repetida em 2019 , com algumas quedas nos índices, marcando $85 \%$ de concordância sobre o aquecimento da Terra (Idem, 2019). Outras quedas apontadas foram em relação ao nível de conhecimento atual. Em 2019, 28\% dos brasileiros estavam bem informados, contra 34\% em 2010.

Não é possível afirmar quais foram os motivos das quedas dos índices de informação e concordância sobre o aquecimento global, afinal, eles não foram abordados pela pesquisa.

\footnotetext{
${ }^{2} \mathrm{O}$ autor da pesquisa utiliza o termo "ceticismo", mas pelo contexto nota-se que são discursos negacionistas.
} 
Podemos, no entanto, apontar algumas relações entre os discursos negacionistas que ocorreram no Brasil na mesma época da última pesquisa.

Em 2019, o ministro das Relações Exteriores, Ernesto Araújo, durante uma palestra em Washington criticou o que chamou de "climatismo", colocando em dúvida o aquecimento global e chamando as preocupações globais de "alarmismo" para fins políticos (DIAS, 2019). Também em 2019, um vereador da cidade do Rio de Janeiro, utilizando a rede social Twitter, questionou o aquecimento global usando como argumento a existência de dias frios ${ }^{3}$. Tendo o presidente norte-americano já criticado o "alarmismo ambiental" dos ambientalistas (COELHO; SALOMÃO, 2020) e utilizado o Twitter para negar as mudanças climáticas mais de uma vez, em uma delas empregando este mesmo argumento de dias frios (MONGE, 2018), esses fatos comuns de comportamentos são reflexos de um alinhamento ideológico entre algumas alas políticas brasileiras e norte-americanas bem definido na literatura, como se verá a seguir.

O atual presidente do Brasil (sem partido) (2019-2022) pauta muitas de suas ações refletidas no comportamento do presidente norte-americano. Se o governo Trump tem demonstrado possuir uma preferência por “(...) lealdade e afinidade ideológica em detrimento da expertise (...)" (KAKUTANI, 2018, p. 40), o mesmo pode ser dito do governo Bolsonaro ao olharmos a sua escalação de escolhas (e demissões) de ministros. Trump se elegeu no meio de uma massiva proliferação de fake news (notícias intencionalmente falsas) que o beneficiou (ALLCOTT; GENTZKOW, 2017), Bolsonaro também (BENITES, 2018). Em relação à política externa brasileira, o ministro Araújo sustenta que o presidente americano é o único governante capaz de liderar o ocidente como civilização, conduzindo o Brasil a um alinhamento sem precedentes à hegemonia e aos interesses norte-americanos (PASSOS; SANTANA, 2018), com uma adesão incondicional à política de Trump (LIMA; ALBUQUERQUE, 2019). Em síntese, “(...) o governo Bolsonaro não apenas se esforça em agradar os EUA, como deseja seguir os seus passos na geopolítica internacional” (GALINARI, 2019, p. 205).

Retomando a discussão sobre o negacionismo de viés partidário, se, nos Estados Unidos, a base republicana reage instantaneamente com uma negação quando se trata de questões que são "do outro lado", como a discussão sobre o controle de armas, o Obamacare ${ }^{4}$ e o aquecimento global, não importando estatísticas, estudos e análises de especialistas (KAKUTANI, 2018), não é uma surpresa encontrar esse mesmo comportamento se repetindo no cenário brasileiro. A exemplo, quando, em 2019, as queimadas na Amazônia tomaram uma

\footnotetext{
${ }^{3} \mathrm{O}$ tweet do vereador Carlos Bolsonaro pode ser encontrado no endereço:

$<$ https://twitter.com/carlosbolsonaro/status/1147863151054073857>. Acesso em: 16 jun. 2020.

4 O Patient Protection and Affordable Care Act é comumente chamado de Obamacare. Trata-se de uma lei federal norte-americana sancionada pelo então presidente Barack Obama em 2010, para regulamentar e controlar os preços dos planos de saúde e abranger uma maior parcela da população nos planos de saúde públicos. Jones, Bradley e Oberlander (2014) discutem com mais detalhes os efeitos da polarização partidária republicanos/ democratas no desenvolvimento político e aceitação popular do Obamacare nos Estados Unidos.
} 
dimensão exorbitante e foram noticiadas pela mídia internacional, declarações infundadas como a de que "a floresta não está pegando fogo" e que as médias das queimadas estavam abaixo das dos últimos anos foram proferidas pelo presidente brasileiro, mesmo com todos os dados científicos apontando o contrário (MAZUI, 2019).

$\mathrm{Na}$ época, nas redes sociais, era comum o discurso dos apoiadores do governo ressoando essa narrativa e defendendo que ou as queimadas realmente não estavam acontecendo ou, mesmo que estivessem, elas eram necessárias para manter o agronegócio e, consequentemente, importante para a economia do país. Esse discurso é igual em sua essência à diferença na aceitação das mudanças climáticas por inclinação partidária que vimos acontecer nos Estados Unidos, além de mais uma vez trazer ao debate a defesa da agenda econômica de colocar o lucro acima da preservação do meio ambiente.

Devido a diversas semelhanças entre as posturas dos governos norte-americano e brasileiro julgamos apropriadas uma transposição entre as análises do negacionismo científico que acontece na esfera política nos Estados Unidos e no Brasil. Entender como o negacionismo foi fomentado pela mídia norte-americana através de um partidarismo político visando defender uma agenda ideológica nos ajuda a compreender os caminhos que o negacionismo percorre no Brasil e como ele se reflete em questões atuais.

Após décadas de ataques, as táticas de se negar a ciência para fortalecer uma agenda neoliberal se difundiram como uma estratégia de sucesso. As polarizações políticas fortalecem um discurso de relativização de resultados científicos, que por sua vez são tratados como uma questão binária de opinião numa luta de "nós contra eles". Ao subverter os dados científicos como passíveis de julgamento individual, a ideologia prevalece sobre a ciência. Nesse contexto de ataque organizado às ciências “(...) a pós-verdade é inevitavelmente o próximo passo" (MCINTYRE, 2018, p. 34, tradução nossa).

Dois grandes eventos marcados pela ofuscação de fatos, pelas mentiras escancaradas e pelo abandono do uso de evidências para estabelecer raciocínios influenciaram a escolha da "pós-verdade" como palavra do ano pelo Dicionário Oxford em 2016: a eleição presidencial dos Estados Unidos e a votação sobre retirar o Reino Unido da União Europeia (Brexit, como ficou conhecido) (D’ANCONA, 2018; MCINTYRE, 2018). A pós-verdade foi, então, definida, como "circunstâncias em que fatos objetivos são menos influentes na formação da opinião pública do que emoções e crenças pessoais" (OXFORD DICTIONARY, 2016, tradução nossa). Este "novo fenômeno" não é bem uma novidade para a comunidade científica que, como destacamos, enfrenta um negacionismo devido a um enviesamento ideológico já há muitos anos. O que vemos com essa chamada era da pós-verdade é uma ampliação da subjetividade da realidade para outros diversos aspectos além da negação das evidências científicas.

Como candidato e nos seus primeiros anos como presidente, $69 \%$ das declarações de Trump foram "predominantemente falsas", "falsas" ou "mentirosas"; e o Brexit triunfou com slogans que eram comprovadamente não verdadeiros ou enganosos (D’ANCONA, 2018, p. 
20). O que era ou não verdade não importou para os eleitores. Ambos os movimentos marcaram um levante popular contra a ordem estabelecida e rumo a algo diferente - porém não bem definido. As narrativas "Tornar a América Grande Novamente" e "Reassumir o Controle" pontuam uma busca popular de tentativa de retorno a um passado que, nesse imaginário coletivo, era melhor ${ }^{5}$. Discursos populistas tendem a ganhar força em tempos de incertezas econômicas e de mudanças culturais e sociais. A extrema direita, utilizando dessa fragilidade para recriar a realidade em seus próprios termos, vende uma realidade alternativa de que brancos sofrem racismo e homens são oprimidos por mulheres, cujos pressupostos são então generalizados em frases de efeito ("Torne a América Grande Novamente", "Reassuma o Controle") que remontam a um período anterior aos movimentos civis feministas, LGBTs e negro (KAKUTANI, 2018).

Essas versões destoantes da realidade, onde nela existem racismos reversos e "femismos", são mais exemplos de como a relativização da verdade extrapolou o âmbito científico para permear os diversos campos de discussões. Os sentimentos de insatisfação das pessoas são explorados e, de certo modo, elas são encorajadas a distorcer a realidade para que ela se encaixe em suas opiniões.

D'Ancona (2018) pontua que, apesar de ser reconfortante imaginar que os eleitores reúnem fatos a respeito de questões e que, a partir da análise de suas conclusões tomam um partido de forma correspondente, o comportamento eleitoral não corresponde a esse ideal. $\mathrm{O}$ que se vê acontecendo na prática são os eleitores primeiro desenvolvendo opiniões e, só então, escolhendo fatos para reforçar essas alegações. Como exemplo, o autor cita como o movimento dos defensores da permanência do Reino Unido na União Europeia cometeu o erro de achar que inundar seus argumentos com dados estatísticos mostrando os benefícios de ser anti-Brexit seria suficiente para alcançar a vitória. Ao se tratar da pós-verdade, o pós não necessariamente indica que passamos pela verdade num sentido temporal, mas sim que ela se tornou irrelevante (MCINTYRE, 2018), o que implica que fatos, dados, ou análises que não têm apelo emocional ou pessoal no qual as pessoas podem se ancorar não se constituirão, para alguns, como fontes robustas e confiáveis de informação.

A pós-verdade indica uma realidade em que os fatos podem ser selecionados, escondidos e manipulados para favorecer a nossa interpretação daquilo que é real. "Dependendo do que se quiser acreditar, alguns fatos importam mais do que outros", afirma McIntyre (2018, p. 10, tradução nossa), ao se referir aos negacionistas climáticos que possuem um padrão duplo de crença, onde simultaneamente acreditam que exista uma conspiração científica alarmista que aumenta o hype 6 das mudanças climáticas, e também escolhem a dedo suas estatísticas científicas preferidas que mostram que a temperatura global

\footnotetext{
5 Essa ideia se associa ao "passado mítico" apontado no livro "Como Funciona o Fascismo" de Jason Stanley (2018).

6 Hype é uma abreviação da palavra hyperbole (hipérbole), que significa exagero. Esta expressão é utilizada como gíria para descrever algo muito comentado, que "está na moda".
} 
não aumentou nos últimos anos. Ou seja, não acreditam na ciência, mas usam alguns dados científicos - descontextualizados e não analisados de forma mais aprofundada - para justificarem sua negação. Orwell em sua obra 1984 também deu nome a esse ato de acreditar em duas coisas simultaneamente contraditórias: duplipensar. Realmente não foi à toa que o livro voltou ao topo.

\section{A relativização e o desgaste da verdade nas bolhas virtuais}

Como uma forma de questionamento sobre como combater o avanço da pós-verdade, há quem procure essa resposta na academia. Como cita McIntyre (2018, p. 123, tradução nossa), é “(...) embaraçoso admitir que uma das tristes raízes do fenômeno da pós-verdade parece ter vindo diretamente das universidades". Ele se refere ao movimento pós-moderno, nascido na academia na segunda metade do século XX.

Não há uma definição exata sobre o pós-modernismo - seria até contraditório com suas próprias ideias se houvesse. Mas podemos entender o movimento como uma rejeição à ideia de verdades absolutas e de uma realidade objetiva; uma busca de desconstrução que analisa um "algo" (seja esse algo escrito, construído ou comportamental) como detentor de premissas políticas, sociais, históricas e culturais em suas fundações. Através de teóricos como Foucault, Lyotard e Derrida, para nomear alguns, a abordagem pós-moderna é a de que não há respostas certas para o que algo "quer dizer", apenas narrativas que permitem múltiplas respostas. Pontuamos os créditos do movimento em estimular o reconhecimento da pluralidade de vozes que compõem nossa sociedade e devem, nela, ter espaço de fala. No entanto, seria "ingênuo negar" que, ao questionar a própria noção de realidade objetiva, esses pensadores desgastaram a noção da verdade (D’ANCONA, 2018, p. 85).

Se tudo é um constructo social, quem vai dizer o que é falso? O discurso de que, se todas as verdades são parciais então não há uma que se sobreponha a outra, foi explorado por aqueles que defendiam teorias desacreditadas ou usada para se comparar o que não poderia ser comparável. Kakutani (2018) menciona como os criacionistas utilizaram o argumento de que "ambos os lados têm o seu valor" para pedir que o criacionismo fosse ensinado nas escolas em contraponto à teoria da evolução, ou como os argumentos pós-modernos validaram a recusa dos adeptos do movimento antivacina e os negacionistas climáticos em aceitar a opinião consensual da maioria dos cientistas.

Não estamos insinuando que movimentos políticos e ideológicos de direita tenham se baseado no academicismo pós-moderno, que tinha como um de seus objetivos proteger as vozes vulneráveis da exploração dos que detinham a autoridade, para justificar seus ataques às ciências. Não imaginamos que os articuladores do movimento antivacina tenham lido Foucault como incentivo de seus ideais. Mas alguma forma simplificada e distorcida desse germe ideológico pós-moderno atravessou os portões universitários e forneceu a ideia que a direita procurava: a de que a ciência não tinha o monopólio sobre a verdade (MCINTYRE, 2018). Essa narrativa foi usada como justificativa pelos apoiadores de Trump ao defender o 
presidente norte-americano e desculpar as suas mentiras. A isso, temos que convir a ironia que é a "(...) apropriação de argumentos pós-modernistas pela direita populista e a sua adoção do repúdio filosófico da objetividade - escolas de pensamentos associadas há décadas à esquerda e aos próprios círculos acadêmicos de elite que Trump e companhia desprezam" (KAKUTANI, 2018, p. 53).

Não apenas uma versão simplificada de um movimento nascido com bases de esquerda é deturpada, difundida e popularizada no outro lado do espectro político e usada como uma justificativa para desacreditar a ciência como uma forma confiável de se olhar a realidade em um momento em que a ciência já está sob ataque há décadas, como todo esse movimento foi acelerado pela popularização do acesso à internet e o surgimento das redes sociais. Em um mundo conectado, qualquer informação, seja ela verdadeira ou não, pode se espalhar por todo o globo em questões de segundos. Além das notícias verdadeiras e falsas se confundirem num mar de informação, redes sociais virtuais agrupam bolhas compostas de pessoas que pensam de modo semelhante e impedem um fluxo de informações plurais.

Pariser (2012) descreve o que passou a chamar de "bolhas de filtros" nas redes sociais: um universo exclusivo para cada um de nós, criado através de algoritmos que selecionam aquilo que nos é mostrado baseado em quem o algoritmo acha que somos ou do que gostamos. Esses algoritmos são retroalimentados, ou seja, quanto mais usamos a internet mais ela tem uma visão de quem nós somos, seja esta correspondente a quem nós próprios achamos que somos ou não.

Desse modo, continua o autor, a tecnologia se coloca entre nós e a realidade que achamos que conhecemos, selecionando notícias que chegam até nossas bolhas e servindo como uma câmera que pode deformar a nossa percepção de mundo. Quanto mais interagimos com certo assunto, mais esse assunto aparecerá em nossas telas.

No mundo da pós-verdade, as fakes news encontraram nas bolhas virtuais um ambiente propício para se proliferarem. Devido a nossa tendência, como seres humanos, de acreditar em informações repetidas - viés da acessibilidade - e de acreditar no que reforça nossas noções preexistentes - viés da confirmação -, são nas bolhas virtuais e na repetição infinita de nós mesmos que as publicações selecionadas por algoritmos nos proporciona que o desgaste da verdade se completa.

Para Dunker (2017, p. 24), uma importante característica da pós-verdade é a “(...) recusa do outro ou ao menos uma cultura da indiferença que, quando se vê ameaçada, reage com ódio ou violência". O problema se torna maior quando tudo é divisível baseado na sua inclinação política, não só questões sobre o que você pensa a respeito de “(...) saúde pública, direitos eleitorais ou aquecimento global, mas também onde você compra, o que come ou a que tipo de filme assiste" (KAKUTANI, 2018, p. 134). Essa polarização dificulta um diálogo entre as partes pois nessa guerra já supõe-se conhecer quem é o oponente. Já sabendo quem ele é, o que ele defende e o que ele vai falar, não é preciso escutá-lo. Dentro dessa cultura de impossibilidade de se escutar o outro, sentimentos de pertencimento são criados participando 
de grupos homogêneos e baseados no ódio contra um inimigo comum (DUNKER, 2017), algo fácil de se construir dentro de um ambiente virtual.

Em qualquer rápida passagem por redes sociais e observando as interações dentro das bolhas, percebe-se a dificuldade em se tentar obter um debate saudável de opiniões. Como Dunker (2017) descreve, para quem está dentro da bolha, não se considera necessário escutar quem está de fora, pois já se julga saber o que vão dizer, uma vez que já se imagina saber quem eles (os outros) são. A grande dificuldade da divulgação científica, dentro desta dimensão da pós-verdade nos nichos das bolhas virtuais, é conseguir furar a bolha e estabelecer um diálogo com quem não quer escutar pois já acredita saber.

Na seção seguinte, relembramos algumas discussões ao apresentarmos exemplos de notícias a respeito da pandemia do novo coronavírus para discutirmos como a ciência e os especialistas são tratados pela mídia e suas repercussões.

\section{O negacionismo governamental do novo coronavírus}

O negacionismo do governo brasileiro frente à pandemia do novo coronavírus é possivelmente o ápice do negacionismo nacional na atualidade, uma vez que suas atitudes e decisões colocam a população brasileira numa posição extremamente vulnerável. Com suas atitudes de desprezo pelo que diz a ciência, o presidente brasileiro se recusa, até então, a decretar um isolamento social para barrar a propagação do vírus e insiste no uso de um medicamento que não possui eficácia comprovada - a hidroxicloroquina (JUCÁ, 2020). O ministro da casa civil (tendo assumido o cargo em fevereiro de 2020 e o ocupando até a data de escrita deste trabalho), Walter Braga Netto, numa tentativa de defender o posicionamento do presidente, proferiu a frase "o presidente não ignora a ciência, (...) ele tem uma visão diferente" (BOLSONARO, 2020). Tal frase premedita e poderia, conceitualmente, ser substituída por "quando formos onipotentes, já não precisaremos da ciência". A única diferença é que, enquanto a primeira foi real, a segunda pertence ao livro 1984 e foi exclamada por um membro do "Partido".

O negacionismo científico da pós-verdade permite que se escolha quais partes da ciência utilizar para sustentar convicções já previamente estabelecidas. Utilizando o recorte desejado, onde a ciência pode ou não sustentar suas crenças, o presidente por vezes escolhe difamar a Organização Mundial de Saúde (OMS), e em outras ocasiões utiliza-se dela para proteger seus interesses. Exemplo disto é não seguir as recomendações da OMS para isolamento social ou para a precaução do uso da hidroxicloroquina nos pacientes de Covid-19, mas escolher uma polêmica declaração da chefe da unidade de doenças emergentes da OMS de que pacientes assintomáticos raramente transmitem o vírus para justificar sua vontade de reabertura de comércios e escolas (LUIZ; TRINDADE, 2020). Após a polêmica da declaração, a OMS se pronunciou alertando que pessoas assintomáticas transmitem sim o vírus. 
Como discutido, tudo pode ser encaixado em caixas de polarização política, não apenas opiniões ideológicas sobre políticas públicas, mas também "opiniões" a respeito de evidências científicas. A polarização entre "direita" e "esquerda", entre "nós" e "eles" se tornou tão escancarada e comum, que se refletiu na declaração, dita durante uma de suas lives semanais em suas redes sociais, sobre o uso da cloroquina: "quem é de direita toma cloroquina, quem é de esquerda, Tubaína”, disse o presidente (LINDNER, 2020). O tom de ironia e brincadeira com o qual proclamou a frase nos mostra quão corriqueiro e banal se tornou a polarização, nos mostra como permeia o coletivo que há realmente uma "guerra" entre direita e esquerda pela vitória da narrativa da verdade.

Mais trabalhos sobre discursos e polarização nas redes virtuais podem ser encontrados em Dibai (2020), onde a autora acompanhou e analisou os conteúdos compartilhados em comunidades on-line de apoio ao governo, encontrando, entre outros resultados, um "medo da esquerda" e concluindo que o partidarismo é um dos principais moderadores da disputa de sentidos nos grupos; em Silva (2020), que analisou o negacionismo histórico presente nas redes digitais bolsonaristas enquanto discursos de manifestação de um populismo digital; e em Cesarino (2019, 2020), que trabalha as características, tanto midiáticas quanto discursivas, do populismo digital bolsonarista. Estes trabalhos reforçam as discussões sobre como as redes sociais são utilizadas como ferramentas de fomento de uma polarização, criando sentimentos de pertencimento entre os grupos confinados nessa mesma bolha.

Bolsonaro imitou os passos de Donald Trump que, no início da pandemia, também minimizou seus perigos, indicou o uso da hidroxicloroquina e seguiu dando declarações polêmicas. Em abril de 2020, o presidente norte-americano sugeriu em uma entrevista que injetar desinfetante poderia servir para o tratamento da Covid-19 (AGÊNCIAS, 2020). Notase que esta declaração exemplifica o "pensamento científico da pós-verdade": há um indício de pensamento científico (pensar no desinfetante como produto contra o vírus), no entanto o questionamento não é aprofundado o suficiente para que faça sentido (injetar no sangue é eficaz para matar um vírus?). Pensa-se apenas em uma verdade descontextualizada e sem uma generalização desse conhecimento, tornando-se um pensamento raso que faz sentido apenas para quem não se debruçar por ele por alguns segundos e seguir uma linha de raciocínio para validá-lo dentro de uma lógica científica. Sem esse questionamento sequencial, o pensamento "científico" inicial pode ser verdadeiro, afinal, desinfetantes matam vírus, logo, por que não os utilizar de qualquer modo?

Parte da mídia norte-americana parece ter aprendido com seus erros anteriores de dar espaço para o outro lado da discussão acreditando que, assim, estariam balanceando o debate. O jornal The New York Times, reagindo a esta declaração de Trump sobre desinfetantes, inicialmente havia escrito um artigo que dizia que "alguns especialistas" enxergavam a ingestão de desinfetante como perigoso. Ao perceber que essa frase poderia ser usada de 
modo a causar a impressão de que havia um debate acerca do assunto, editaram a reportagem removendo a sentença? ${ }^{7}$.

A mídia nacional, contudo, continua a abrir espaço para que os "dois lados" sejam ouvidos e, com isso, alimenta a ilusão de que análises científicas a respeito do isolamento social são uma questão de opinião. Em maio de 2020, dois ex-ministros do governo Bolsonaro, Luiz Henrique Mandetta (ex-ministro da Saúde) e Osmar Terra (ex ministro da Cidadania), participaram do GloboNews Debate. Na ocasião, Terra criticou as táticas de isolamento e disse que, além de ineficaz, a quarentena trouxe prejuízos para a atividade econômica. Ao trazer à tona a questão do prejuízo econômico, nota-se mais um exemplo do discurso do negacionismo científico como arma de proteção da agenda neoliberal.

Apesar dos exemplos destacando ataques à ciência, com aspectos políticos que podem levar a prejuízos sociais incalculáveis, há de se destacar uma surpresa esperançosa. $\mathrm{O}$ programa de televisão Roda Viva, da emissora TV Cultura, entrevistou o biólogo virologista e divulgador científico Átila Iamarino em abril de 2020, para um debate sobre a pandemia do novo coronavírus. O programa teve os seus maiores índices de audiência desde julho de 2018, quando o entrevistado foi o então candidato à presidência Jair Bolsonaro. No canal oficial do Roda Viva no YouTube, o vídeo de Atila é o segundo mais visto, com (até o momento em que este texto foi escrito) 3,6 milhões de visualizações, ficando atrás da entrevista de Bolsonaro, contudo na frente de ambas as entrevistas do ex-juiz e ex-ministro da Justiça Sérgio Moro - a de 2018 com 3 milhões de visualizações e a de 2020, com 2,1 milhões de visualizações ${ }^{8}$. A entrevista de Átila chegou aos tópicos mais comentados do mundo na rede social Twitter, o que incentivou ao canal permitir a entrevista alongar-se por 10 minutos a mais do que o previsto dada a sua relevância.

Destaca-se, aqui, o simbolismo de um divulgador científico obter mais visualizações do que o que, até o momento da entrevista, era uma pessoa símbolo do governo Bolsonaro (o ex-juiz Sérgio Moro). A entrevista do Atila obteve, relativamente, tamanho sucesso que o apresentador de televisão Ratinho escreveu em sua rede pessoal do Twitter que a entrevista foi "boa e esclarecedora" e que deveríamos "rever atitudes e comportamentos" 9 . É necessário refletir sobre essa importância simbólica, uma vez que não podemos considerar tal acontecimento "apenas um tweet", e sim analisar o contexto político e histórico no qual ele se encontra. Na época das bolhas virtuais da pós-verdade, em que especialistas são apenas mais um com sua opinião, é de se pesar a importância da divulgação científica chegar até o outro lado da bolha.

\footnotetext{
${ }^{7}$ A declaração do jornal The New York Times de que removeram essa frase para evitar uma impressão de que há um debate acerca do assunto pode ser encontrada em seu perfil oficial do Twitter, disponível em: $<$ https://twitter.com/nytimes/status/1253719616603541504>. Acesso em: 16 jun. 2020.

8 Os vídeos do programa Roda Viva podem ser encontrados em seu canal do YouTube disponível em: $<$ https://www.youtube.com/user/rodaviva>. Acesso em: 16 jun. 2020.

9 Os tweets estão disponíveis em: < https://twitter.com/ratinhodosbt/status/1244816939802931202> e $<$ https://witter.com/ratinhodosbt/status/1244816338025152513>. Acesso em: 16 jun. 2020.
} 
O apresentador Ratinho havia entrevistado Bolsonaro em seu programa de televisão uma semana antes da entrevista de Átila ir ao ar; seu filho Carlos Roberto Massa Júnior, conhecido como Ratinho Júnior, é governador do Paraná (Partido Social Democrático) (20192022) e alinhado ao governo Bolsonaro. Essa divulgação científica do Roda Viva conseguiu adentrar momentaneamente nessa bolha e o comentário do apresentador apareceu para seu um milhão de seguidores que, com base no alinhamento ideológico da rede $\mathrm{SBT}^{10}$, podemos supor ter uma parte considerável formada por apoiadores do governo Bolsonaro.

Não seremos ingênuos de argumentar que uma única entrevista de uma hora e meia é de algum modo plenamente suficiente para que pessoas revejam e mudem suas concepções e posicionamentos políticos e/ou ideológicos. No entanto, tal como nos estudos de mudanças conceituais visando uma alfabetização científica considera-se a necessidade de múltiplos conflitos cognitivos para que o sujeito repense suas concepções, aqui também acreditamos no potencial positivo que essa entrevista - e tantas outras formas de divulgação científica - pode ter produzido.

\section{Reflexões finais}

Dunker (2017) possui uma visão um pouco diferente da relação entre pós-verdade e pós-modernismo da qual discutimos anteriormente. Para o autor, "a pós-verdade é o falso contrário necessário do pós-modernismo. (...) uma espécie de reação nos termos de uma demanda de real, de um retorno aos valores orgânicos e suas pequenas comunidades de consenso" (Idem, p. 8). Nesses termos, a pós-verdade é uma reação à flexibilização da realidade que a pós-modernidade ofereceu, onde as pequenas comunidades de consenso podem ser identificadas nas bolhas virtuais das redes. Com tantas opções do que o real pode ser, os consensos da pós-verdade, mesmo que remotos, trazem um chão firme para se pisar. Dunker (2017) classifica a pós-verdade como a segunda onda da pós-modernidade. Deste modo, aqui teorizamos a possibilidade de que ocorra, num futuro, uma terceira onda da pósmodernidade, em que voltamos à uma busca dos fatos como fatores estruturantes da realidade. Uma reação às verdades provisórias da pós-verdade que vemos agora.

Por hora, devemos encarar a pós-verdade e enfrentar as enxurradas de informações falsas que as redes virtuais contêm. Com as sobrecargas de informações que os indivíduos se deparam ao acessar a rede, eles devem sempre realizar uma análise crítica daquilo que encontram se não querem cair em fake news. "Ensinar a navegar na web com discernimento é a missão cultural mais urgente de nossa época” aponta D’Ancona (2018, p. 101), e continua:

\footnotetext{
10 Sílvio Santos vetou críticas ao presidente brasileiro, chamando-o de seu "patrão", além de ter seu genro nomeado como titular da pasta do Ministério das Comunicações do governo Bolsonaro. É seguro afirmar a existência de um alinhamento ideológico entre a emissora SBT e o atual (2019-2022) mandato presidencial. Estas informações estão disponíveis em <https://f5.folha.uol.com.br/colunistas/cristina-padiglione/2020/04/ recado-de-silvio-santos-sobre-bolsonaro-faz-aumentar-tensao-no-sbt.shtml $>$ e $\quad<$ https://noticias.uol.com.br/ politica/ultimas-noticias/2020/06/10/bolsonaro-recria-ministerio-das-comunicacoes-com-genro-de-silviosantos.htm>. Acesso em: 16 jun. 2020.
} 
"os melhores podcasts já proporcionam ajuda nessa tarefa (...). Em sua simplicidade e objetividade, essa nova forma de conteúdo (...) é o descendente punk do diálogo socrático" (Idem). Se os tempos mudam, que nos adaptemos a eles para que não percamos a voz e fiquemos de fora dessa revolução.

“A pós-verdade é, acima de tudo, um fenômeno emocional. Diz respeito à nossa atitude em relação à verdade, e não à própria verdade. A partir disso, deveria ficar claro que o contra ataque tem que ser emocionalmente inteligente e também rigorosamente racional" (Ibidem, p. 111). D’Ancona nos chama a atenção da necessidade de entrar no jogo de modo competitivo, por vezes utilizando personagens carismáticos para propagar o discurso científico, do mesmo método que muitas vezes o negacionismo utiliza (o autor se refere ao movimento antivacina que possui entre seus adeptos celebridades que captam a atenção e a emoção da população). É um chamado para que entremos em campo. Já vimos que apenas estatísticas e dados não bastam para convencer, é preciso encontrar maneiras de aproximar o conhecimento científico ao emocional do grande público.

Ao longo de seu livro, McIntyre (2018) descreve a atuação de um professor de educação básica do quinto ano que ensinou seus alunos a reconhecer uma notícia falsa. Não há truque algum nisso e, como comenta, uma criança é capaz de fazer essas ações, das quais aqui destacamos algumas: procurar múltiplas fontes; olhar a data de publicação; analisar a expertise do autor com o assunto. São questionamentos básicos. Por vezes, assumimos erroneamente que as novas gerações já nascem "digitalmente alfabetizadas", quando não. É necessário que se ensine como questionar a validade do que se vê nos ambientes virtuais, estamos, afinal, na pós-verdade.

Em suma, não é uma surpresa que a melhor forma de enfrentar a pós-verdade é através da educação e da estimulação e desenvolvimento de um pensamento crítico. Contudo, devido a polarização em que nos encontramos, é necessário utilizarmos de estratégias que permitam que não somente o "outro lado" nos escute como também que a alfabetização crie condições para que possamos evitar que aspectos da pós-verdade continuem a se desenvolver.

Não é plausível considerarmos que consigamos agradar a todos e produzir um discurso científico neutro, que sustente ambos os lados argumentativos de um espectro político tão polarizado quanto vemos hoje, pois estaríamos desconsiderando o caráter histórico e contextual da ciência. No entanto, é necessário utilizarmos de estratégias que permitam a compreensão de que seu caráter parcial não reflete ataques infundados a ideias opostas, mas sim que compõe um conjunto de conhecimentos e saberes que podem e devem ser utilizados para a construção e desenvolvimentos de raciocínios argumentativos. Dentre as estratégias, destacamos as propostas de divulgação científica em diferentes frentes, perpassando o uso mais intenso de canais de comunicação das universidades, até a inserção de temáticas sociocientíficas em canais midiáticos abertos, com o uso de representações acessíveis do ponto de vista midiático e que se aproximem de uma população outrora sem acesso a um determinado conjunto de informações. 
Kahan, Jenkins-Smith e Braman (2011) pontuam que, apesar dos indivíduos possuírem uma tendência a rejeitar informações vindas de especialistas que possuem valores opostos aos seus próprios, os mesmos tendem a serem mais receptivos com as informações de um debate se percebem que, neste debate, há especialistas com valores diversos nos dois lados da discussão. Como destacam Kahan et al. (2012), essa diversidade cultural dos comunicadores possibilita uma maior afinidade e aproximação com diferentes comunidades, aumentando a credibilidade que os ouvintes fornecem ao debate. Deste modo, a porta que conduz a um início de debate não é automaticamente fechada pelo "outro" ao julgar que o assunto se encontra no "campo adversário". Para os autores, aperfeiçoar essas técnicas de comunicação por meio de uma nova ciência da comunicação científica é um bem público de importância singular.

A entrevista de Iamarino ao Roda Vida é um exemplo do potencial da divulgação científica de alcançar diferentes nichos ideológicos. Acreditamos na hipótese de que, pelo entrevistado ter evitado ataques unilaterais ao governo, debatendo como a pesquisa e a educação brasileira são sucateadas há tempo, manteve-se aberta a porta da possibilidade para que os espectadores mais alinhados aos grupos de direita e ao bolsonarismo se interessassem pelo assunto. Interesse esse que se encontra refletido nos comentários do apresentador Ratinho em suas redes sociais, que possui uma representatividade dentro de uma certa bolha ideológica.

Claramente há não apenas incertezas neste campo, como também a necessidade de se pensar em um projeto educacional a longo prazo que não se limite ao trabalho com mídias em detrimento a um projeto de educação que incorpore essas discussões nos espaços formativos formais.

Ao fim do livro 1984, o personagem principal é capturado pelo "Partido", torturado e forçado a treinar para não enxergar argumentos contraditórios entre si. "O 'Partido' diz que a Terra é plana, o 'Partido' diz que o gelo é mais pesado que a água”, ele repete para si ao treinar não ver as contradições dos argumentos que visa interiorizar. $\mathrm{Na}$ atual conjuntura que vivemos, estes treinamentos acontecem implicitamente ao nos vermos dentro de uma polarização que reproduz a falácia da falsa dicotomia, onde se você não está de um lado, automaticamente está do outro e deve concordar com o que este lado fala, ignorando as contradições dos argumentos do lado em que você não está. Nesta guerra dos "doisladismos", não se busca um refinamento do entendimento da realidade, mas sim a vitória da narrativa pessoal. A não ser que consigamos quebrar essa tendência viciosa, a ciência e o pensamento científico continuarão sob ataque. Para que isso não aconteça, por mais cansativo que por vezes seja, não podemos desistir do debate.

\section{Referências bibliográficas}

AGÊNCIAS. Trump sugere tratar coronavírus com "injeção de desinfetante" ou com luz solar. El País, Washington, 24 de abr. de 2020, Pandemia de Coronavírus. Disponível em: 
$<$ https://brasil.elpais.com/internacional/2020-04-24/trump-sugere-tratar-o-coronavirus-comuma-injecao-de-desinfetante-ou-com-luz-solar.html>. Acesso em: 16 jun. 2020.

ALLCOTT, H; GENTZKOW, M. Social Media and Fake News in the 2016 Election. Journal of Economic Perspectives, v. 31, n. 2, p. 211-236, 2017.

ALTARES, G. '1984' lidera as vendas de livros nos EUA desde a posse de Trump. El País, Madri, 27 de jan. 2017. Cultura. Disponível em:

$<$ https://brasil.elpais.com/brasil/2017/01/26/cultura/1485423697_413624.html >. Acesso em: 16 mai. 2020.

ASSOCIATED PRESS. 'Trump of the Tropics': five things you should know about Brazilian leader Jair Bolsonaro's visit with Donald Trump. South China Morning Post, 20 de mar. de 2019, World. Disponível em: <https:/www.scmp.com/news/world/united-states-canada/ article/3002421/trump-tropics-five-things-you-should-know-about $>$. Acesso em: 24 set. 2020.

BENITES, A. A máquina de 'fake news' nos grupos a favor de Bolsonaro no WhatsApp. El País, Brasília, 28 de set. de 2018, Política. Disponível em: $<$ https://brasil.elpais.com/brasil/2018/09/26/politica/1537997311_859341.html>. Acesso em: 16 jun. 2020.

BINDING, L. 'Trump of the Tropics' - Controversial quotes by Brazil's new president Jair Bolsonaro. Sky News, 1 de jan. de 2019, World. Disponível em: $<$ https://news.sky.com/story/trump-of-the-tropics-controversial-quotes-by-brazils-newpresident-jair-bolsonaro-11539063>. Acesso em: 21 jun. 2020.

BOLSONARO não ignora ciência, só vê diferente, diz ministro. Terra, 15 de maio de 2020, Brasil. Disponível em: <https://www.terra.com.br/noticias/brasil/bolsonaro-nao-ignoraciencia-so-ve-diferente-diz-ministro, 1da17eb13b710f1 ee0e302ba1073d006il brtm3q.html>. Acesso em: 16 jun. 2020.

BUCCI, E. Existe democracia sem verdade factual? Barueri: Estação das Letras e Cores, 2019. $104 \mathrm{p}$.

BULLA, B; CHADE, J. EUA e Europa se dividem em relação a 'Trump tropical'. Estadão, 04 de nov. 2018, Economia. Disponível em: <https://economia.estadao.com.br/noticias/ geral,eua-e-europa-se-dividem-em-relacao-a-trump-tropical,70002583684>. Acesso em: 24 set. 2020. 
CAMillo, J; MATTOS, C. Educação em Ciências e a Teoria da Atividade Cultural: contribuições para a reflexão sobre tensões na prática educativa. Revista Ensaio, Belo Horizonte, v. 16, n. 1, p. 211-230, jan-abr. 2014.

CESARINO, L. Identidade e representação no bolsonarismo. Revista de Antropologia, São Paulo, v. 62, n. 3, p. 530-557, 2019.

CESARINO, L. Como vencer uma eleição sem sair de casa: a ascensão do populismo digital no Brasil. Internet \& sociedade, v. 1, n. 1, p. 91-120, 2020.

COELHO, L; SAlOMÃO, A. Trump diz a Fórum de Davos para rejeitar alarmismo ambiental. Folha de S. Paulo, 21 de jan. de 2020, Mundo. Disponível em: $<$ https:/www1.folha.uol.com.br/mundo/2020/01/eua-voltaram-a-vencer-diz-trump-emmensagem-que-mirou-publico-domestico-em-davos.shtml>. Acesso em: 28 set. 2020.

COHEN, S. States of Denial: Knowing about Atrocities and Suffering. Oxford, GBR: John Wiley \& Sons, 2013.

COOK, J. el al. Quantifying the consensus on anthropogenic global warming in the scientific literature. Environmental Research Letters, v. 8, n. 2, maio, 2013. Disponível em: $<$ https://iopscience.iop.org/article/10.1088/1748-9326/8/2/024024>. Acesso em: 16 jun. 2020.

D'ANCONA, M. Pós-verdade: a nova guerra contra os fatos em tempos de fake news. Tradução: Carlos Szlak. Barueri: Faro Editorial, 2018. 142 p.

DATAFOLHA. Para $85 \%$ dos brasileiros, planeta está ficando mais quente. Instituto de Pesquisas DataFolha, São Paulo, 27 de jul. de 2019, Opinião Pública. Disponível em: $<$ http://datafolha.folha.uol.com.br/opiniaopublica/2019/07/1988289-para-85-dos-brasileirosplaneta-esta-ficando-mais-quente.shtml>. Acesso em: 16 jun. 2020.

DATAFOLHA. 90\% já ouviram falar em aquecimento global. Instituto de Pesquisas DataFolha, São Paulo, 23 de abr. de 2010, Opinião Pública. Disponível em: $<$ http://datafolha.folha.uol.com.br/opiniaopublica/2010/04/1223567-90-ja-ouviram-falar-emaquecimento-global.shtml>. Acesso em: 16 jun. 2020.

DIAS, M. Nos EUA, Ernesto critica 'climatismo' e diz que debate é 'pretexto para ditadura'. Folha de S. Paulo, 11 de set. de 2019, Mundo. Disponível em: $<$ https://www1.folha.uol.com.br/mundo/2019/09/nos-eua-araujo-critica-climatismo-e-diz-quedebate-e-pretexto-para-ditadura.shtml>. Acesso em: 16 jun. 2020. 
DIBAI, P. Bolsonarismo on-line: “Com ou sem democracia, salvemos o capitão!”. Tensões Mundiais, Fortaleza, v. 16, n. 30, p. 177-211, 2020.

DUNKER, C. Subjetividade em tempos de pós-verdade. In: DUNKER, C. et al. (Org). Ética e pós-verdade. Porto Alegre: Dublinense, 2017. cap. 1, p. 7-38.

ENGLISH OXFORD living dictionaries. Word of the Year 2016 is... 2016. Disponível em: $<$ https://languages.oup.com/word-of-the-year/2016/>. Acesso em: 27 mai. 2020.

FUNK, C.; KENNEDY, B. How Americans see climate change and the environment in 7 charts. Pew Research Center, 21 de abr. de 2020. Disponível em: $<$ https://www.pewresearch.org/fact-tank/2020/04/21/how-americans-see-climate-change-andthe-environment-in-7-charts/>. Acesso em 16 de jun. de 2020.

GALINARI, T. N. A "Guinada à direita" e a nova política externa brasileira. Caderno de Geografia, v. 29, Número Especial 2, p. 190-211, 2019.

GASTALDI, F. C. Gramsci e o negacionismo climático estadunidense: a construção do discurso hegemônico do antropoceno. Revista Neiba, Cadernos Argentina Brasil, v.7, n. 1, 2018. Disponível em: <https://www.e-publicacoes.uerj.br/index.php/neiba/article/view/ 39247>. Acesso em: 16 jun. 2020.

JONES, D. K.; BRADLEY, K. W. V; OBERLANDER, J. Pascal's Wager: health insurance exchanges, Obamacare, and the Republican dilemma. Journal of Health Politics, Policy and Law, v. 39, n. 1, p. 97-137, 2014.

JUCÁ, B. Bolsonaro amplia uso da cloroquina admitindo que pode não ter eficácia e trazer efeitos colaterais graves. El País, São Paulo, 20 de maio de 2020, Pandemia do Coronavírus. Disponível em: <https://brasil.elpais.com/brasil/2020-05-20/bolsonaro-amplia-uso-dacloroquina-admitindo-que-pode-nao-ter-eficacia-e-trazer-efeitos-colaterais-graves.html>. Acesso em: 16 jun. 2020.

KAHAN, D. M. Ideology, motivated reasoning, and cognitive reflection. Judgment and Decision Making, v. 8, n. 4, p. 407-424, jul. 2013.

KAHAN, D. M. et al. The polarizing impact of science literacy and numeracy on perceived climate change risks. Nature climate change, v. 2, n. 10, p. 732-735, 2012. 
KAHAN, D. M; JENKINS-SMITH, H; BRAMAN, D. Cultural cognition of scientific consensus. Journal of Risk Research, v. 14, n. 2, p. 147-174, 2011.

KAKUTANI. M. A Morte da Verdade: notas sobre a mentira da Era Trump. Tradução: André Czarnobai; Marcela Duarte. Rio de Janeiro: Intrínseca, 2018. 168 p.

LIMA, M. R. S; ALBUQUERQUE, M. O Estilo Bolsonaro de Governar e a Política Externa. Boletim OPSA, n. 1, p. 15-21, jan./mar. 2019.

LINDNER, J. 'Quem é de direita toma cloroquina, quem é de esquerda, Tubaína', diz Bolsonaro sobre liberação. Estadão, Brasília, 19 de maio de 2020, Saúde. Disponível em: $<$ https://saude.estadao.com.br/noticias/geral,quem-e-de-direita-toma-cloroquina-quem-e-deesquerda-tubaina-diz-bolsonaro-sobre-liberacao,70003308307>. Acesso em: 16 jun. 2020.

LUIZ, W; TRINDADE, N. Bolsonaro fala em reabrir escolas após OMS citar estudo inconclusivo que lança dúvidas sobre transmissão assintomática. O Globo, Brasília, 09 de jun. de 2020, Sociedade. Disponível em: $<$ https://oglobo.globo.com/sociedade/bolsonaro-falaem-reabrir-escolas-apos-oms-citar-estudo-inconclusivo-que-lanca-duvidas-sobre-transmissaoassintomatica-24469994?>. Acesso em: 16 jun. 2020.

MAZUI, G. Bolsonaro diz que 'floresta não está pegando fogo', mas sim as áreas desmatadas. G1, Brasília, 24 de ago. de 2019, Política. Disponível em: <https:/g1.globo.com/politica/ noticia/2019/08/24/bolsonaro-diz-que-floresta-nao-esta-pegando-fogo-mas-sim-as-areasdesmatadas.ghtml>. Acesso em: 16 jun. 2020.

MCINTYRE, L. Post-truth. Cambridge: The MIT Press, 2018. 241 p.

MONGE, Y. Trump sobre relatório climático do seu Governo: "Não acredito". El País, Washington, 27 de nov. de 2018, Meio Ambiente. Disponível em: $<$ https://brasil.elpais.com/brasil/2018/11/27/internacional/1543283242_634443.html>. Acesso em: 16 jun. 2020.

ORESKES, N. The Scientific Consensus on Climate Change. Science, v. 306, n. 5702, p. 1686, dez. 2003. Disponível em: <https://science.sciencemag.org/content/306/5702/1686>. Acesso em: 16 jun. 2020.

ORESKES, N.; CONWAY, E. M. Merchants of Doubt: how a handful of scientists obscured the truth on issues from tobacco smoke to global warming. New York: Bloomsbury Press, 2010. 360 p. 
ORLANDI, E. O. Discurso, Imaginário Social e Conhecimento. Em Aberto, Brasília, ano 14, n.61, jan./mar. p. 52-59, 1994

ORWELL, G. 1984. São Paulo: Companhia das Letras, 2009.

PAINTER, J. Poles Apart: the international reporting of climate scepticism. Reuters Institute for the Study of Jornalism, Oxford, 2011. $136 \mathrm{p}$

PARISER, E. O filtro invisível: o que a internet está escondendo de você. Tradução: Diego Alfaro. Rio de Janeiro: Zahar, 2012. 250 p.

PASSOS, R. D. F; SANTANA, D. P. F. Uma breve análise das propostas de Jair Bolsonaro para a política externa brasileira. Perspectivas, São Paulo, v. 52, p. 89-101, jul./dez, 2018.

PHILLIPS, T. Trump of the tropics: the 'dangerous' candidate leading Brazil's presidential race. The Guardian, Boa Vista, 19 de abr. de 2018, World. Disponível em: $<$ https:/www.theguardian.com/world/2018/apr/19/jair-bolsonaro-brazil-presidentialcandidate-trump-parallels $>$. Acesso em: 24 set. 2020.

RABIN-HAVT, A. Lies, Incorporated: The World of Post-Truth Politics. New York: Anchor Books, 2016. 227 p.

SANT'ANNA, L. Bolsonaro reforça imagem de "Trump tropical”. CNN, 24 de abr. de 2020, Internacional. Disponível em: <https://www.cnnbrasil.com.br/internacional/2020/04/24/ bolsonaro-reforca-imagem-de-trump-tropical>. Acesso em: 24 set. 2020.

SILVA, D. C. P. Embates semiótico-discursivos em redes digitais bolsonaristas: populismo, negacionismo e ditadura. Trabalhos em Linguística Aplicada, v. 59, n. 2, p. 1171-1195, 2020 .

STANLEY, Jason. Como funciona o fascismo: A política do "nós" e "eles". L\&PM Pocket, 2018.

SUN, L. H; EILPERIN, J. CDC gets list of forbidden words: Fetus, transgender, diversity. The Washington Post, 15 de dez. 2017, Health Science. Disponível em: $<$ https:/www.washingtonpost.com/national/health-science/cdc-gets-list-of-forbidden-wordsfetus-transgender-diversity/2017/12/15/f503837a-e1cf-11e7-89e8-edec16379010_story.html> Acesso em: 27 mai. 2020. 
THEEL, S.; GREENBERG, M.; ROBBINS, D. Study: Media Sowed Doubt in Coverage of UN Climate Report. Media Matters, 10 de out. de 2013. Disponível em: $<$ https://mediamatters.org/research/2013/10/10/study-media-sowed-doubt-in-coverage-of-unclima/196387>. Acesso em: 16 jun. 2020. 